\title{
АНАЛИЗ БИЗНЕС-ПРОЦЕССОВ ПРЕДПРИЯТИЯ: ОПИСАНИЕ, ЦЕЛИ, МЕТОДИКА
}

\section{(c) 2020 Пайтаева Комета Тахировна}

кандидат экономических наук, доцент кафедры «Учёт, анализ и аудит в цифровой экономике», Институт экономики и финансов Чеченский государственный университет, Россия, Грозный

E-mail:kometa_1972@mail.ru

В данной статье рассматриваются особенности анализа бизнес-процессов на предприятии. Раскрыто понятие бизнес-процесса, рассмотрено значение бизнес-плана. Обозначена и обоснована необходимость разработки и внедрения стратегических решений, среди которых большую роль играет внедрение процессного подхода.

Ключевые слова: бизнес-процесс, процессный подход, рыночная стоимость предприятия, бизнес-план, финансовое состояние, управленческие решения.

Эффективность функционирования и развития экономических субъектов различных форм собственности и видов экономической деятельности в значительной степени определяется тем, насколько рационально организованы и реализуются бизнес-процессы. Андерсен Бьерн считает, что «бизнес-процесс представляет собой цепь логически связанных повторяющихся действий, в результате которых используются ресурсы предприятия для переработки объекта с целью достижения определенных измеримых результатов для удовлетворения внутренних или внешних потребителей» [1].

Рыночные условия хозяйствования повышают значение аналитического обоснования выбора управленческих решений. Анализ необходим для разработки бизнес-планов, для контроля за их выполнением и для оценки эффективности их реализации.

Для успешного функционирования предприятия большое внимание должно уделяться непрерывному анализу его финансового состояния, на основании которого будут приняты соответствующие управленческие решения, обеспечивающие платежеспособный уровень. Перспектива существования и функционирования предприятия напрямую зависит также от того, насколько грамотно составлен бизнес-план. Под бизнес-планом понимается точное и понятное описание предполагаемого бизнеса в краткой форме. Бизнес-план является важным инструментом, помогающим выбрать из большого количества различных ситуаций наиболее перспективный вариант решения и определить средства для его достижения.

С одной стороны, бизнес-план предопределяет пошаговое исполнение экономического замысла и для этого производится детальное планирование производственной деятельности предприятия с учетом всех сопутствующих факторов, включая наличие квалифицированного персонала, финансовых и материальных ресурсов, определение своего сегмента на рынках сбыта продукции. При этом разрабатываются превентивные меры по преодолению всех возможных препятствий для достижения желаемых производственных и финансовых результатов.

С другой стороны, бизнес-план показывает инвесторам, что планируемое предприятие имеет достаточно надежную, эффективную и последовательную «дорожную карту» достижения поставленных целей и задач предлагаемого проекта.

Именно для этих целей бизнес-план должен содержать исчерпывающую информацию по всем сторонам планируемой производственной деятельности, которая при детальном анализе должна убедить потенциальных пользователей в реальности его исполнения и получения прибыли от вложенных в данный проект денежных средств.

Анализ финансового состояния даёт понять, какова рыночная стоимость компании, насколько она может расплачиваться по своим обязательствам, степень ее финансовой устойчивости. Этот вид анализа является необходимым как для собственников и менеджеров предприятия в плане дальнейшего управления им, так и для ин- 
весторов, потребителей и поставщиков, которые на основе данных анализа могут сделать выводы о дальнейшем взаимодействии с компанией.

Встречается также такое понятие как бизнеспотенциал, представляющее функционал компании, т.е. набор тех бизнес-функций, функций управления и функций обеспечения, которые необходимы для поддержания видов коммерческой деятельности. Рентабельность, ликвидность, платежеспособность, финансовая устойчивость являются показателями классического (традиционного) финансового анализа, который в настоящее время не потерял своей актуальности и является хоть не единственным, но базовым для эффективного менеджмента предприятия.

В современных условиях функционирования, отличающихся реформированием принципов деятельности организаций и предприятий, возрастает значимость перехода их к созданию такой системы управления, которая будет опираться на аналитическое обоснование принимаемых решений с учетом оперативных и стратегических целей, соответствующих рыночным потребностям и определением путей их реализации [4].

Осуществляя управленческую деятельность в нынешних реалиях, экономические субъекты прибегают к разработке и внедрению стратегических решений. Среди них большую роль играет процессный подход, посредством которого организация получает доступ к новым ресурсам и возможностям, что приводит к повышению эффективности ее деятельности за счет обновления товарного ассортимента. Процессная модель управления подразумевает анализ бизнеспроцессов предприятия.

Процессный подход организации деятельности хозяйствующего субъекта подразумевает, что все составляющие его функционирования выстраиваются в единую систему взаимосвязанных и взаимозависимых процессов, содержат в себе значительные возможности для оптимизации бизнес-процессов, сокращения затрат, повышения эффективности деятельности структурных подразделений, создания модели функционирования, максимально адаптированной к потребностям клиентов. Очевидно, что на практике потенциальные преимущества процессного подхода могут быть реализованы при условии адекватного комплексного информационно-аналитического сопровожде- ния бизнес-процессов организации.

По мнению Варзунова А.В., Торосян Е.К., Сажневой Л.П., процессный подход основан на следующих принципах:

1. Деятельность компании рассматривается как совокупность бизнес-процессов. Принцип определяет видение деятельности компании как совокупности бизнес-процессов. Именно он определяет новую культуру восприятия организации при процессном подходе.

2. Выполнение бизнес-процессов подлежит обязательной регламентации или формальному описанию. Регламент бизнес-процесса - это документ, описывающий последовательность операций, ответственность, порядок взаимодействия исполнителей, порядок принятия решений по улучшению бизнес-процесса.

3. У каждого бизнес-процесса есть внутренний или внешний клиент и владелец. Выделение бизнес-процесса всегда связано с выявлением клиента или потребителя результата процесса, имеющего для него определенную стоимость. Кроме клиента каждый бизнес-процесс имеет владельца - должностное лицо, которое имеет в своем распоряжении необходимые ресурсы, управляет ходом бизнес-процесса и несет ответственность за результаты и эффективность бизнес-процесса. Владелец бизнес-процесса является должностным лицом, формальным лидером, поэтому он имеет необходимые полномочия, располагает требуемыми для реализации процесса ресурсами, управляет ходом бизнеспроцесса и несет ответственность за его результат.

4. Каждый бизнес-процесс характеризуется ключевыми показателями, описывающими его исполнение, результат или влияние на итог деятельности организации в целом [3].

Благодаря информационно-аналитическому сопровождению бизнес-процессов реализуются следующие функции:

1) инструментальная, целевой установкой которой является разработка приемов и методов сбора, обработки, анализа и систематизации полученных данных;

2) коммуникативная, которая в современных условиях позволяет осуществлять обмен информацией о требованиях рынка и быстро реагировать на происходящие изменения;

3) организационно-технологическая, представляющая собой совокупность средств, которые определяют механизм достижения конкрет- 
ного результата;

4) интеграционная, посредством которой происходит установление связей организации с поставщиками и потребителями;

5) познавательная, связанная с отражением и интерпретацией действительности.

Следовательно, грамотно организованная информационно-аналитическая поддержка бизнес-процессов, нацеленных на достижение экономическим субъектом определенных результатов, способствует дальнейшему совершенствованию системы управления.

Безусловно, наибольший удельный вес среди информационных источников занимают данные бухгалтерского учета и отчетности. Учетная служба выполняет ряд функций, которые облегчают принятие управленческих решений руководством организации, поскольку основывается на принципах достоверности, полноты, своевременности и т.д.

Используя полученную информацию об использовании ресурсов, можно выявить узкие места и комплексно воздействовать на негативные факторы. Следует помнить, что главное не только определить, в каком подразделении возникло отклонение, но также важно провести факторный анализ и установить все причины, обусловившие это отклонение.

При этом процессный подход отличается от существовавшего ранее функционального подхода тем, что деятельность экономического субъекта анализируется как совокупность определенного количества операций и процессов, реализуемых на разных уровнях управления. Это обстоятельство обусловлено тем, что процессный подход, в отличие от функционального, позволяет перейти от управления структурами к управлению действиями. Функциональная модель подразумевает представление компании как совокупности подразделений, имеющих только вертикальные взаимосвязи и не использующих горизонтальные взаимозависимости.

Бариленко В.И., Бердников В.В., Булыга Р.П. полагают, что «процесс разработки и реализации стратегии в большей степени нуждается не в копировании ранее успешных бизнесмоделей других компаний, а во внимательном изучении результатов их применения, гибком целеполагании, идентификации критических факторов успеха, определении узких мест в бизнес-структуре, моделировании альтернатив развития и мониторинга, связанных с использо- ванием рисков» [2].

Таким образом, оценка деятельности предприятия характеризуется с помощью процессных моделей, исследование которых позволяет сделать выводы о необходимости повышения их эффективности в результате увеличения суммы прибыли, минимизации затрат, повышения качества выпускаемой продукции, роста уровня потенциала предприятия. Поэтому для исследования каждого из перечисленных направлений необходимо изучение бизнес-процессов компании с позиции их взаимной интеграции.

Как известно, существует несколько основных групп приемов, использование которых позволяет проводить анализ бизнес-процессов. K первой группе относятся качественные методы анализа, такие как SWOT-анализ, направленный на выявление слабых и сильных сторон, возможностей и угроз для предприятия. Вторая группа приёмов отражает количественный анализ, характеризует целесообразность бизнеспроцессов, отличается высокой степенью эффективности применения и точными результатами при анализе реализации продукции, изучении предпочтений потребителей.

Кроме того, в процессе моделирования бизнес-процессов предприятия специалисты применяют вертикальное и горизонтальное описание. Вертикальный тип основывается на отображении работ и составлении их порядка в форме построения дерева бизнес-процессов. Между несколькими основными действиями имеют место лишь вертикальные связи. Горизонтальное описание бизнес-процессов отражает степень взаимосвязи между отдельными функциями предприятия, ключевые информационные потоки, характеризующие объект исследования, а также порядок выполнения основных задач.

Исходя из вышеизложенного и опираясь на теоретические аспекты, касающиеся бизнеспроцессов предприятия, можно сделать вывод о том, что данные вопросы достаточно сложны в использовании и играют существенную роль в деятельности компании.

Применение технологий бизнес-аналитики для информационно-аналитической поддержки бизнес-процессов в организации требует принятия комплекса соответствующих решений организационно-методического и информационноаналитического характера.

Данные анализа бизнес-процессов вы- 
ступают основным источником информации для осуществления процессного управления организацией. В свою очередь, полученная информация является основой информационноаналитического обеспечения всех бизнес-

процессов организации. Ключевой цельюданной процедуры является изучение последовательности применения технологий анализа бизнеспроцессов для информационно-аналитического

\section{Библиографический список}

1. Андерсен Б. Бизнес-процессы. Инструменты совершенствования/ Андерсен Б. - М.: РИА «Стандарты и качество», 2003.- 272 с.

2. Бариленко В.И., Бердников В.В., БулыгаР.П. Основы бизнес-анализа: учебное пособие под ред. В.И.Бариленко.-М.: КНОРУС, 2014.-272 с.

3. Варзунов А.В., Торосян Е.К., СажневаЛ.П. Анализ и управление бизнес-процессами: учебное пособие.СПб: Университет ИТМО, 2016.-112 с.

4. Пайтаева К. Т. Сравнительный обзор методик анализа финансового состояния организации// Экономические науки. - № 181.-2019.- С. 136-140. 